\title{
Effect of unilateral ovariectomy on the population of ovarian follicles relative to age in the Mongolian gerbil (Meriones unguiculatus)
}

\author{
M. L. Norris and C. E. Adams \\ A.R.C. Institute of Animal Physiology, Animal Research Station, 307 Huntingdon Road, \\ Cambridge CB3 OJQ, U.K.
}

\begin{abstract}
Summary. Ovarian follicles were counted and classified in control and unilaterally ovariectomized Mongolian gerbils, which had ceased to breed, at 306-1020 days and 340-902 days of age respectively. With increasing age there was a steady reduction in the non-antral follicle population, but a reduction in the number of antral follicles only occurred in extreme old age. Approximately twice as many non-antral follicles were present in control as in unilaterally ovariectomized females of similar ages, whereas the number of antral follicles was similar in both groups. There were no instances of total depletion of the follicle stock, the lowest numbers recorded being 288 and 74 in control and unilaterally ovariectomized females respectively.
\end{abstract}

\section{Introduction}

At birth or shortly thereafter, female mammals have a finite stock of ovarian follicles which is slowly and continuously depleted throughout life. The number of follicles and their contained oocytes which reach maturity and ovulate is relatively small and insignificant, the vast majority of oocytes being lost by atresia. This continual loss of oocytes can be slowed down experimentally, e.g. by hypophysectomy (Jones \& Krohn, 1959), but it cannot be stopped. Loss of oocytes begins in intrauterine life, and continues at a rate apparently determined by the genetic make-up of the species or strain (Jones, 1970). Strain differences have been shown to exist in the mouse, in both the initial endowment of oocytes and their rate of loss (Jones \& Krohn, 1961).

Quantitative studies have been made on the effects of increasing age and parity on the oocyte population in rats (Mandl \& Shelton, 1959; Shelton, 1959) and mice (Jones \& Krohn, 1961), and oocyte loss following unilateral ovariectomy has been examined in the rat (Arai, 1920; Mandl \& Zuckerman, 1951; Mandl, Zuckerman \& Patterson, 1952) and mouse (Jones \& Krohn, 1960).

We have shown that the lifetime reproductive performance of unilaterally ovariectomized Mongolian gerbils is only slightly inferior to that of their controls, with a general decline in fertility only becoming evident in the oldest females (Norris \& Adams, 1982). In this species no information is available on the ovarian follicle population. The present report examines the relationship between increasing age and the ovarian follicle population in control and unilaterally ovariectomized females which had ceased to breed. 


\section{Materials and Methods}

A total of 50 ovaries from 25 control females (Group A) and 32 ovaries from unilaterally ovariectomized females (Group B) was obtained from gerbils whose lifetime reproductive performance was under investigation (Norris \& Adams, 1982). All animals came from our own colony, the management of which has been described elsewhere (Norris \& Adams, 1972a). Group B females were unilaterally ovariectomized 1 week before pairing at 100 days of age when, like Group A females, they were paired with proven males and maintained monogamously.

The ovaries used in this study were from animals aged 306-1020 days (Group A) and 340-902 days (Group B) when reproduction ceased. Ovaries were removed, fixed in Bouin's solution, dehydrated, cleared and embedded. Paraffin-wax blocks were serially sectioned at $8 \mu \mathrm{m}$, stained with Delafield's haematoxylin and counterstained with chromotrope 2R. Subsequently, the ovaries were given the original animal number, and dealt with in a random manner. The age of the females at autopsy was calculated after all of the counts had been made. Follicle estimates were then made using the multiplication method of Zuckerman (1951), with a correction applied for overcounting (Abercrombie, 1946).

The follicles were counted and classified into 4 groups using a simplification of the systems proposed by Hansson (1947) for the mink, and Pedersen \& Peters (1968) for the mouse (Table 1). Initially, using a group of 5 ovaries, duplicate counts of all non-antral follicles were made on every 5th and every 10th section. After correction, similar results were obtained both in terms of total numbers of follicles, and the relative proportions of different follicle types. Accordingly, follicles of types 1-3 were counted in every 10th section, and the appropriate adjustments made. Oocyte diameters ranged from about $20 \mu \mathrm{m}$ (type 1 follicles) to $62-70 \mu \mathrm{m}$ (type 4 follicles), which apparently represents the maximum size attained before follicle rupture, as indicated by the mean vitelline diameter of $69 \mu \mathrm{m}$ reported by Marston \& Chang (1966) for newly ovulated, unpenetrated gerbil eggs.

Table 1. Relationship of the system devised by Pedersen \& Peters (1968) for the classification of mouse ovarian follicles with that used in the present study of the gerbil

\begin{tabular}{ccccl}
\hline \multicolumn{2}{c}{ Pedersen \& Peters (1968) } & & \multicolumn{2}{c}{ Present system } \\
\cline { 1 - 2 } \cline { 5 - 6 } Follicle type & \multicolumn{1}{c}{ Description } & & Follicle type & Description \\
\hline $1-3 \mathrm{a}$ & $0-20$ cells & & 1 & Small \\
$3 \mathrm{~b}-4$ & $21-100$ cells & & 2 & Medium \\
$5 \mathrm{a}-5 \mathrm{~b}$ & Non-antral, $\geqslant 101$ cells & & 3 & Large \\
$6-8$ & Antral follicles & & 4 & Graafian \\
\hline
\end{tabular}

Difficulty was experienced in locating the nucleolus (about $2 \mu \mathrm{m}$ ) in many type 1 follicles, and the oocyte nucleus was used as the counting marker. Follicle types 2 and 3 were counted using the nucleolus $(4-5 \mu \mathrm{m})$ as the marker, whereas type 4 follicles, due to their relatively low incidence, large size and very distinct nucleoli, were counted in every section and no adjustments made.

Diagnosis of the start of atresia in the early stages of follicular development was extremely uncertain. However, the later stages were easily identifiable because of the indistinct basement membrane, marked breakdown of the granulosa cells and, usually, a very degenerate oocyte with an irregular outline and vacuolated, granular ooplasm. Follicles in such an obviously advanced state of atresia were too irregular to classify and had to be omitted from the counts. 
Morphologically, these atretic follicles equate with the late stage II, and more especially with the stage III atretic follicles, described by Byskov (1974) for the mouse ovary.

A regression analysis was performed on the total numbers of follicles counted.

\section{Results}

As shown in Table 2, in both groups of females there was a steady decrease in the numbers of follicles present with increasing age, the lowest numbers recorded being 288 (Group A) and 74 (Group B). No instances of total oocyte depletion were noted. Throughout the age range there were approximately twice as many non-antral follicles per female present in Group $A$ as in Group B females, but the number of antral follicles remained similar, a decrease only becoming evident in the oldest females from both groups.

Table 2. Number and type of follicles present in the ovaries of Mongolian gerbils with 2 ovaries (Group A) or 1 ovary (Group B) relative to age

\begin{tabular}{|c|c|c|c|c|c|c|c|c|c|c|}
\hline \multirow{3}{*}{$\frac{\text { Group }}{\mathrm{A}}$} & \multirow{4}{*}{$\frac{\text { Age (days) }}{300-399}$} & \multirow{3}{*}{$\begin{array}{c}\begin{array}{c}\text { No. of } \\
q \uparrow\end{array} \\
+2\end{array}$} & \multirow{3}{*}{$\begin{array}{c}\begin{array}{c}\text { No. of } \\
\text { follicles/ } \\
\text { female }\end{array} \\
1763,2319\end{array}$} & \multicolumn{7}{|c|}{ No. of follicles/female } \\
\hline & & & & \multicolumn{2}{|c|}{ Type 1} & \multicolumn{2}{|c|}{ Type 2} & Type 3 & \multicolumn{2}{|c|}{ Type 4} \\
\hline & & & & 1562,2022 & $(88)$ & 72,207 & (7) & 60,96 & 30,33 & (1) \\
\hline & & 1 & 1150 & 903 & (79) & 103 & (9) & $120 \quad(10)$ & & (2) \\
\hline & $500-599$ & 5 & $1380 \pm 202$ & $1094 \pm 178$ & (79) & $139 \pm 34$ & (10) & $120 \pm 12$ & $27 \pm 4$ & (2) \\
\hline & $600-699$ & 3 & $1153 \pm 280$ & $854 \pm 211$ & (74) & $148 \pm 29$ & (13) & $113 \pm 43(10)$ & $37 \pm 9$ & (3) \\
\hline & $700-799$ & 5 & $683 \pm 116$ & $462 \pm 90$ & (68) & $101 \pm 18$ & (15) & $98 \pm 20(14)$ & $23 \pm 3$ & (3) \\
\hline & $800-899$ & 5 & $568 \pm 31$ & $359 \pm 15$ & (63) & $125 \pm 26$ & (22) & $70 \pm 18(12)$ & $14 \pm 2$ & (3) \\
\hline & $900-999$ & 2 & 357,483 & 181,301 & (57) & 66,90 & (19) & $72,91 \quad(19)$ & 19,20 & (5) \\
\hline & $1000-1099$ & 2 & 288,505 & 160,271 & (54) & 60,121 & (23) & $60,91 \quad(19)$ & 8,22 & (4) \\
\hline \multirow[t]{7}{*}{ B } & $300-399$ & 2 & 754,869 & 479,727 & (75) & 97,164 & (16) & 24,78 & 21,33 & (3) \\
\hline & $400-499$ & 1 & 626 & 405 & (65) & 104 & (17) & (14) & & (4) \\
\hline & $500-599$ & 8 & $603 \pm 65$ & $424 \pm 53$ & (70) & $95 \pm 8$ & (16) & $62 \pm 11(10)$ & $22 \pm 2$ & (4) \\
\hline & $600-699$ & 6 & $490 \pm 53$ & $323 \pm 43$ & (66) & $87 \pm 12$ & (18) & $54 \pm 11(11)$ & $25 \pm 1$ & (5) \\
\hline & $700-799$ & 12 & $457 \pm 38$ & $318 \pm 28$ & (70) & $61 \pm 8$ & (13) & $60 \pm 9 \quad(13)$ & $18 \pm 2$ & (4) \\
\hline & $800-899$ & 2 & $74, \overline{168}$ & 26,86 & (46) & 24,49 & (30) & 12,18 & 12,15 & (11) \\
\hline & $900-999$ & 1 & 195 & 81 & (42) & 55 & (28) & (21) & 17 & (9) \\
\hline
\end{tabular}

Values are mean \pm s.e.m. $(\%)$.

In the Group A and Group B females there was a steady decline in the proportion of Type 1 follicles with increasing age, and a concomitant increase in the proportion of the other types present (Table 2). The distribution of the number of follicles per female relative to age, together with calculated regression lines and associated data for follicle depletion over the period of examination are shown in Text-fig. 1. The regressions clearly show that the rate of follicle loss is approximately twice as great in Group A as in Group B females.

\section{Discussion}

The depletion of the oocyte stock in the Mongolian gerbil, as presently observed, is considered to be primarily due to ageing of the female, as in the rat (Shelton, 1959) and mouse (Jones \& Krohn, 1961), in which the effect of reproduction on the depletion of oocytes was shown to be insignificant.

The decision to exclude only follicles in the final stages of atresia was due to difficulties 


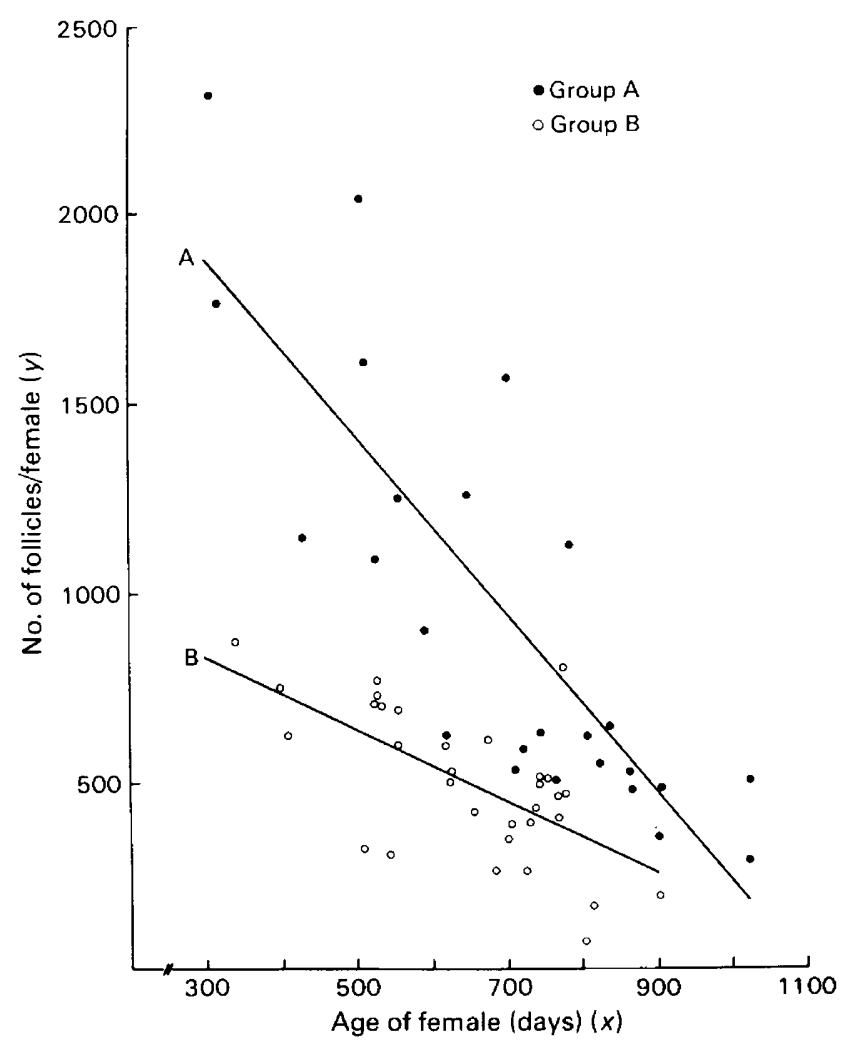

Text-fig. 1. The number of ovarian follicles present in Mongolian gerbils of different ages and with 2 ovaries (Group A) or 1 ovary (Group B). The regression lines shown are $y=$ $2587-2.364 x, r=-0.829$ (Group A); and $y=1123-0.965 x, r=-0.649$ (Group B).

experienced both in diagnosing early atresia in the smallest (and most numerous) follicles and the often impossible task of classifying the excluded follicles. Similar difficulties in recognizing early atresia, and the subjective criteria used to assess the normality of an oocyte, resulting in individual variation in interpretation, have been reported for rodent ovaries (Mandl \& Zuckermann, 1950; Jones \& Krohn, 1959). The proportion of 'normal' oocytes in the mouse ovary is reported as $50-60 \%$ (Jones \& Krohn, 1961), and this proportion increases as the total number diminishes with increasing age in nulliparous and multiparous rats (Mandl \& Shelton, 1959; Shelton, 1959). Based on these results, estimates of the number of 'normal' gerbil oocytes would apparently require the total count to be halved. Even so, this would still leave plenty of 'normal' follicles and oocytes in all of the females examined. Furthermore, the presence of follicles in all stages of development indicates that lack of follicular development was not responsible for the cessation of reproduction; similar findings have been reported for the rat (Mandl \& Shelton, 1959) and mouse (Jones \& Krohn, 1960). In the Mongolian gerbil, the mean age at final conception for control females is 437 days, and for unilaterally ovariectomized females 392 days (Norris \& Adams, 1982). The present estimates show that at these ages females still have $>1000$ and $>800$ follicles respectively, and any decrease in the antral follicle population would not be expected to occur for about another 300 days.

An average of about 20 antral follicles per female was counted in control and unilaterally ovariectomized gerbils, whereas there were approximately twice as many non-antral follicles per female in the control group. This effective doubling of the number of antral follicles after 
unilateral ovariectomy has been reported as being due either to a decrease in follicular atresia in the hamster (Greenwald, 1961), or to an increase in the developmental recruitment of smaller, non-antral follicles in the guinea-pig and rat (Hermreck \& Greenwald, 1964; Peppler \& Greenwald, 1970). There are two main concepts regarding the control of events following unilateral ovariectomy; (1) a fall in the level of ovarian steroids results in an increased output of pituitary gonadotrophin, or (2) the same level of gonadotrophin acts on half the amount of target tissue, thereby resulting in a doubling of the effect.

Our present results fully agree with the view of Zuckerman (1951), that although the remaining ovary following unilateral ovariectomy may double in weight, there is no increase in the total oocyte number. In fact, as Arai (1920) and Mandl \& Zuckerman (1951) found in the rat, the present results for unilaterally ovariectomized gerbils show a slightly lower follicle number present compared with the mean ovarian number from intact females. However, the present observed increase in the number of antral follicles following unilateral ovariectomy equates well with an approximate doubling both in the number of corpora lutea, and in the ovarian weight (Norris \& Adams, 1982). Due to their size and persistence the corpora lutea contribute most towards the observed increase in ovarian weight, with the large numbers of antral follicles being secondary. Even though a reduction was found in the number of antral follicles present in extremely aged control and unilaterally ovariectomized gerbils, the numbers were always well in excess of the ovulation rate for this species, a rate which does not appear to alter throughout life (Norris \& Adams, 1982). This is in agreement with the findings of Biggers, Finn \& McLaren (1962) that the ovulation rate does not differ between young and old mice, even though a decrease in the number of Graafian follicles occurs in old age (Jones \& Krohn, 1961).

No marked differences were noted in either the topical or histological appearance of ovaries from control and unilaterally ovariectomized gerbils. It has been reported that spontaneous neoplasms typically appear in gerbils after 2 years of age, with the ovary showing the highest incidence (Benitz \& Kramer, 1965). The most commonly reported neoplasms are granulosa and lutein cell tumours and ovarian leiomyoma (Benitz \& Kramer, 1965; Ringler, Lay \& Abrams, 1972), but Benitz \& Kramer (1965) also found that whereas 13\% of their aged females had ovarian tumours, over $60 \%$ had ovarian cysts. In the present study, $9 \%$ of the control and $23 \%$ of the unilaterally ovariectomized gerbils aged up to 700 days had unilaterally cystic ovaries, whereas $79 \%$ ( $36 \%$ both ovaries) of the control, and $40 \%$ of the unilaterally ovariectomized gerbils aged over 700 days had cystic ovaries; we have previously reported that both the incidence and severity of ovarian cysts are strongly age dependent (Norris \& Adams, 1972b). Although the occurrence of ovarian cysts does exert an adverse effect on reproduction (Norris \& Adams, 1972b), this is not considered primarily responsible for the cessation of reproduction in the present study.

Our results for the Mongolian gerbil fully supported the general conclusion of Jones (1970), that the adverse effects of ovarian ageing in laboratory rodents are not the immediate cause of the decline in reproduction, since reproduction has ceased long before these effects have become apparent.

We thank Mr D. E. Walters, A.R.C. Statistics Group, Department of Applied Biology, University of Cambridge, for statistical advice.

\section{References}

Abercrombie, M. (1946) Estimation of nuclear population from microtome sections. Anat. Rec. 94, 239-247.
Arai, H. (1920) On the cause of the hypertrophy of the surviving ovary after semi-spaying (albino rat) and on the number of ova in it. Am. J. Anat. 28, 59-79. 
Benitz, K.F. \& Kramer, A.W. (1965) Spontaneous tumours in the Mongolian gerbil. Lab. Anim. Care 15, 281-294.

Biggers, J.D., Finn, C.A. \& McLaren, A. (1962) Long-term reproductive performance of female mice. II. Variation of litter size with parity. J. Reprod. Fert. 3, 313-330.

Byskov, A.G. (1974) Cell kinetic studies of follicular atresia in the mouse ovary. J. Reprod. Fert. 37, 277-285.

Greenwald, G.S. (1961) Quantitative study of follicular development in the ovary of the intact or unilaterally ovariectomized hamster. J. Reprod. Fert. 2, 351361.

Hansson, A. (1947) The physiology of reproduction in mink (Mustela vison. Schreb.) with special reference to delayed implantation. Acta zool. 28, 1-136.

Hermreck, A. \& Greenwald, G.S. (1964) The effects of unilateral ovariectomy on follicular maturation in the guinea pig. Anat. Rec. 148, 171-176.

Jones, E.C. (1970) The ageing ovary and its infiuence on reproductive capacity. $J$. Reprod. Fert., Suppl. 12, 17-30.

Jones, E.C. \& Krohn, P.L. (1959) Influence of the anterior pituitary on the ageing process in the ovary. Nature, Lond. 183, 1155-1158.

Jones, E.C. \& Krohn, P.L. (1960) The effect of unilateral ovariectomy on the reproductive lifespan of mice. $J$. Endocr. 20, 129-134.

Jones, E.C. \& Krohn, P.L. (1961) The relationships between age, numbers of oocytes and fertility in virgin and multiparous mice. J. Endocr. 21, 469-495.

Mandl, A.M. \& Shelton, M. (1959) A quantitative study of oocytes in young and old nulliparous laboratory rats. J. Endocr. 18, 444-450.

Mandl, A.M. \& Zuckerman, S. (1950) The numbers of normal and atretic ova in the mature rat. $J$. Endocr. $6,426-435$.
Mandl, A.M. \& Zuckerman, S. (1951) Numbers of normal-and atretic oocytes in unilaterally spayed rats. J. Endocr. 7, 112-119.

Mandl, A.M., Zuckerman, S. \& Patterson, H.D. (1952) The number of oocytes in ovarian fragments after compensatory hypertrophy. J. Endocr. 8, 347-356.

Marston, J.H. \& Chang, M.C. (1966) The morphology and timing of fertilization and early cleavage in the Mongolian gerbil and deer mouse. J. Embryol. exp. Morph. 15, 169-191.

Norris, M.L. \& Adams, C.E. (1972a) The growth of the Mongolian gerbil Meriones unguiculatus, from birth to maturity. J. Zool., Lond. 166, 277-282.

Norris, M.L. \& Adams, C.E. (1972b) Incidence of cystic ovaries and reproductive performance in the Mongolian gerbil, Meriones unguiculatus. Lab. Anim. 6, 337-342.

Norris, M.L. \& Adams, C.E. (1982) Lifetime reproductive performance of Mongolian gerbils (Meriones unguiculatus) with 1 or 2 ovaries. Lab. Anim. 16, $146-150$.

Pedersen, T. \& Peters, H. (1968) Proposal for a classification of oocytes and follicles in the mouse ovary. J. Reprod. Fert. 17, 555-557.

Peppler, R.D. \& Greenwald, G.S. (1970) Influence of unilateral ovariectomy on follicular development in cycling rats. Am. J. Anat. 127, 9-14.

Ringler, D.H., Lay, D.M. \& Abrams, G.D. (1972) Spontaneous neoplasms in aging gerbillinae. Lab. Anim. Sci. 22, 407-414.

Shelton, M. (1959) A comparison of oocytes in nulliparous and multiparous senile laboratory rats. $J$. Endocr. 18, 451-455.

Zuckerman, S. (1951) The number of oocytes in the mature ovary. Recent Prog. Horm. Res. 6, 63-109.

Received 15 January 1982 